\title{
Um ensaio sobre a paralisia agitante*
}

James Parkinson

\section{Prefácio}

As vantagens que derivaram do cuidado com o qual afirmações hipotéticas são admitidas, não são de modo algum mais óbvias do que naquelas ciências que mais particularmente pertencem à arte da cura. É, portanto, necessário que alguma explanação conciliatória seja oferecida para a presente publicação, na qual se reconhece que a mera conjetura toma o lugar do experimento, e que a analogia é o substituto para o exame anatômico, única base segura para o conhecimento patológico.

Entretanto, quando a natureza do objeto e as circunstâncias nas quais é mencionado são consideradas, espera-se que a apresentação das seguintes páginas ao público médico não seja severamente censurada. A doença, a respeito da qual a presente investigação é realizada, é de natureza altamente aflitiva. Não obstante esse fato, ela ainda não obteve um lugar na classificação dos nosologistas. Alguns consideraram seus sintomas característicos como doenças distintas e diferentes, e outros deram o seu nome a doenças que diferem essencialmente dela. Enquanto isso, o infeliz sofredor a considera um flagelo, do qual não tem perspectiva de fugir.

* Publicado originalmente em 1817, em Londres. Tradução para o português, de Luana Villac. 


\section{CLÁSSICOS DA PSICOPATOLOGIA}

A doença tem longa duração. Portanto, relacionar os sintomas que ocorrem em seus estágios finais com aqueles que marcam o seu início requer uma observação contínua do mesmo caso ou, pelo menos, um histórico correto de seus sintomas, mesmo durante vários anos. $\mathrm{O}$ autor teve a oportunidade de se beneficiar de ambas as vantagens e foi, consequentemente, levado particularmente a observar vários outros casos nos quais a doença existia em diferentes estágios de evolução. Por meio dessas observações repetidas, espera ter sido levado a uma conjetura provável sobre a natureza da enfermidade e que a analogia tenha sugerido meios que poderiam ser produtivos para aliviar e talvez até curar a doença, se empregados antes de a doença ter há muito se instalado. Ele, portanto, considera ser um dever submeter suas opiniões ao exame dos outros, mesmo em seu atual estado de imaturidade e imperfeição.

Postergar sua publicação certamente não pareceu ser justificável. A doença escapou de uma observação particular, e a tarefa de determinar a sua natureza e causa por meio da investigação anatômica não parece passível de ser assumida por aqueles que, a partir de suas habilidades e oportunidades, tinham maior probabilidade de realizá-la. Que esses amigos da humanidade e da ciência médica, que já nos revelaram muitos dos processos mórbidos pelos quais a saúde e a vida são abreviadas, possam estar animados em estender suas pesquisas a esta enfermidade, foi muito desejado, e espera-se que isso possa ser conseguido por meio da publicação destas observações.

Se a informação necessária for assim obtida, o autor não reclamará de nenhuma censura que a publicação precipitada de meras sugestões conjeturais possa gerar, mas considerar-se-á totalmente recompensado por ter chamado a atenção daqueles que possam apontar os meios mais apropriados para aliviar uma enfermidade fastidiosa e muito angustiante.

\section{ÍNDICE}

CAP. I - Definição - Histórias - Casos Ilustrativos

CAP. II - Sintomas Patognomônicos Examinados - Tremor Coactus - Scelotyrbe Festinans

CAP. III - Paralisia agitante diferenciada de outras doenças com as quais pode ser confundida

CAP. IV - Causa imediata - Causas remotas - Casos Ilustrativos

CAP. V - Considerações com respeito aos meios de cura 


\section{Um ensaio sobre a Paralisia Agitante}

\section{Capítulo I}

\section{Definição - História - Casos Ilustrativos Paralisia Agitante (Paralysis Agitans)}

Movimentos trêmulos involuntários, que reduzem a potência muscular, em partes que não estão em ação e mesmo quando apoiadas; com a propensão para curvar o tronco à frente e de passar de um ritmo de caminhada a um ritmo de corrida: sem prejudicar os sentidos e o intelecto.

O termo paralisia agitante tem sido vagamente empregado por autores médicos em geral. Por alguns, ele foi utilizado para designar casos comuns de Paralisia, na qual ocorreram alguns tremores leves; enquanto, por outros, foi aplicado a certas afecções anômalas não pertencentes à Paralisia.

$\mathrm{O}$ tremor dos membros pertencente a esta doença foi particularmente notado, como será visto ao tratar dos sintomas, por Galen, que marcou o seu caráter peculiar por um termo apropriado. O mesmo sintoma, também se verá, foi precisamente tratado por Sylvius de la Boë. Juncker também parece ter mencionado este sintoma: tendo dividido o tremor em ativo e passivo, ele diz sobre o último, "ad affectus semiparalyticos pertinent; de qualibus hic agimus, quique tremores paralytoidei vocantur." Tremor foi adotado como um gênero por quase todos os nosologistas, mas sempre não marcado, em suas várias definições, pelas características que incluiriam esta doença. O celebrado Cullen, com sua precisão costumeira, observa: "Tremorem, utpote semper symptomaticum, in numerum generum recipere nollem; species autem a Sauvagesio recensitas, prout mihi vel astheniæ vel paralysios, vel convulsionis symptomata esse videntur, his subjungam". ${ }^{1}$ Tremor pode de fato apenas ser considerado um sintoma, embora devam ser admitidas várias espécies deste. No presente exemplo, a agitação produzida pela espécie particular de tremor que ocorre aqui é escolhida para dar o epíteto pelo qual esta espécie de paralisia pode ser distinguida.

${ }^{1}$ Synopsis Nosologiæ Methodicæ, Tom. ii, p. 195. 


\section{CLÁSSICOS DA PSICOPATOLOGIA}

\section{História}

Tão leves e quase imperceptíveis são as primeiras incursões desta enfermidade, e tão extremamente vagarosa é sua evolução, que raramente é possível para o paciente formar qualquer lembrança do período preciso do seu início. Os primeiros sintomas percebidos são um leve senso de fraqueza, com a propensão para o tremor em algumas partes em particular; algumas vezes na cabeça, porém mais usualmente em uma das mãos e um dos braços. Esses sintomas gradualmente aumentam na parte primeiramente afetada; e em um período incerto, porém raramente em menos do que 12 meses ou mais, a influência mórbida é sentida em alguma outra parte. Assim, pressupondo-se que uma das mãos e um dos braços sejam primeiro afetados, a outra mão ou braço se torna similarmente afetada nesse período. Após alguns poucos meses, o paciente torna-se menos rígido do que o normal em manter uma postura ereta: isto é mais observável enquanto ele caminha, mas algumas vezes enquanto está sentado ou em pé. Algum tempo após o aparecimento desse sintoma, e durante sua lenta progressão, uma das pernas começa a tremer levemente, e também começa a sofrer fadiga antes da outra perna, e, em alguns meses, esse membro se torna agitado por tremores similares e sofre uma perda similar de potência.

Até então, o paciente terá, no entanto, vivenciado poucos inconvenientes; e sob a forte influência da perseverança habitual, talvez raramente pense que está sendo objeto da doença, exceto quando relembrado pela falta de firmeza da sua mão, ao escrever ou ao realizar qualquer tipo de manipulação. Entretanto, conforme a doença evolui, atividades similares são realizadas com dificuldade considerável, com a mão falhando em responder com exatidão aos ditados da vontade. Caminhar se torna uma tarefa que não pode ser realizada sem uma atenção considerável. As pernas não são elevadas naquela altura ou com a prontidão que se deseja, sendo, portanto, necessário o maior cuidado para evitar quedas frequentes.

Nesse período, o paciente vivencia muitos inconvenientes, o que infelizmente aumenta dia após dias. A submissão dos membros às ordens da vontade é dificilmente conseguida no desempenho das tarefas mais simples da vida. Os dedos não podem ser dispostos nas direções propostas e apontados com certeza em direção a qualquer ponto. Conforme o tempo e a doença avançam, as dificuldades aumentam: escrever agora só é possível com muita difículdade; e ler, devido aos movimentos trêmulos, é possível com alguma dificuldade. Enquanto isso, às refeições, o garfo que não é devidamente direcionado frequentemente falha em elevar o bocado de comida do prato que, quando garfado, é levado com muita dificuldade à boca. Nesse período, o paciente raramente experimenta a interrupção da agitação de seus membros. Começando, por exemplo, em um braço, 
a cansativa agitação é suportada até muito além do sofrimento, quando através de uma mudança súbita de postura ela para por alguns instantes naquele membro, para iniciar, geralmente em menos de um minuto, em uma das pernas ou no outro braço. Atormentado por esse círculo vicioso, o paciente recorre à caminhada, um modo de exercício em relação ao qual os sofredores desta doença são geralmente parciais. Devido à sua atenção ser por meio dela desviada dos sentimentos desagradáveis, pelo cuidado e esforço exigidos para garantir seu desempenho seguro.

Entretanto, na medida em que a enfermidade evolui, mesmo essa mitigação temporária do sofrimento da agitação dos membros é negada.

A propensão para curvar-se para frente torna-se invencível, e o paciente é então forçado a pisar com os dedos e a parte da frente dos pés, enquanto a parte superior do corpo é jogada tão à frente que se torna difícil evitar uma queda com o rosto no chão. Em alguns casos, quando esse estágio da enfermidade é alcançado, o paciente não pode mais se exercitar caminhado da sua maneira usual, sendo, no entanto, jogado sobre os dedos e a parte da frente dos pés, sendo, ao mesmo tempo, irresistivelmente impelido a dar passos mais rápidos e curtos e, portanto, a adotar um ritmo indesejado de corrida. Em alguns casos, torna-se necessário substituir totalmente a corrida pela caminhada; caso contrário, o paciente ao caminhar apenas alguns passos inevitavelmente cairia.

Nesse estágio, o sono se torna muito conturbado. Os movimentos trêmulos dos membros ocorrem durante o sono e aumentam até que despertem o paciente, e frequentemente com muita agitação e alarme. $\mathrm{O}$ poder de levar a comida à boca é tão prejudicado que ele é obrigado a consentir que outros o alimentem. Os intestinos, que estiveram entorpecidos, agora, na maioria dos casos, demandam medicamentos consideravelmente fortes para estimulá-los: a expulsão das fezes do reto algumas vezes requer uma ajuda mecânica. Conforme a doença evolui em direção ao seu estágio final, o tronco está quase que permanentemente curvado, a potência muscular está decididamente mais reduzida e a agitação trêmula se torna violenta. O paciente agora caminha com grande dificuldade; não mais capaz de apoiar-se em sua bengala, ele não ousa mais se aventurar em um exercício, a menos que ajudado por um cuidador, que caminhando de costas à sua frente evita que o paciente caia para frente, pressionado suas mãos contra a parte frontal de seus ombros. Suas palavras são agora dificilmente inteligíveis, e ele não só não é capaz de se alimentar, mas quando o alimento é levado à sua boca são tantas as ações dos músculos da língua, da faringe, impedidas pela ação prejudicada e pela agitação interminável, que o alimento é retido com dificuldade na boca até ser mastigado e, então, com a mesma dificuldade, engolido. Agora também, devido à mesma causa, outra circunstância muito desagradável ocorre: a saliva falha em ser direcionada à parte posterior das fauces, e assim baba continuamente da boca, misturada com as partículas do alimento, que ele não é mais capaz de tirar de dentro da boca. 


\section{CLÁSSICOS DA PSICOPATOLOGIA}

Conforme a debilidade aumenta e a influência da vontade sobre os músculos desaparece, a agitação trêmula se torna mais veemente. Ela agora raramente o deixa por um momento. Entretanto, mesmo quando exausto, a natureza rouba boa parte do sono, o movimento se torna tão violento que sacode não apenas a cama, como também o piso e os caixilhos do quarto. O queixo está agora quase sem movimento, caído sobre o esterno. As papinhas com as quais se tenta alimentá-lo, junto com a saliva, escorrem continuamente da boca. A força da articulação é perdida. As urinas e as fezes saem involuntariamente; e, por fim, a sonolência constante, com um leve delírio, e outras marcas da exaustão extrema anunciam a tão desejada libertação.

\section{Caso I}

Quase todas as circunstâncias notadas na descrição anterior foram observadas em um caso que ocorreu há vários anos e que, devido aos sintomas particulares que se manifestaram em sua evolução, ao pouco conhecimento sobre sua natureza admitido pelo médico que o atendeu e ao modo do seu fim, resultou em um desejo ávido de obter algum conhecimento extra sobre a sua natureza e causa.

O paciente deste caso era um homem de pouco mais de 50 anos de idade, que exerceu diligentemente a profissão de jardineiro, levando uma vida de moderação e sobriedade notáveis. O início da enfermidade foi primeiro manifestado por um ligeiro tremor da mão e do braço esquerdos, uma circunstância que ele atribuiu ao fato de ter realizado por vários dias um tipo de trabalho que exigiu considerável esforço daquele membro. Embora muitas vezes questionado, ele não se lembrou de nenhuma outra circunstância que possa considerar como tendo provavelmente causado sua enfermidade. Ele não sofreu muito com o reumatismo nem teve dores de cabeça, nem qualquer convulsão súbita que poderia ser chamada de apoplexia ou hemiplegia. Nesse caso, todas as circunstâncias que foram mencionadas na história anterior ocorreram.

\section{Caso II}

O paciente do caso que foi em seguida observado foi casualmente encontrado na rua. Era um homem de 62 anos de idade que passou a maior parte da vida trabalhando como assistente no gabinete de um magistrado. Ele estava sofrendo da doença havia oito ou dez anos. Todas as extremidades estavam 
consideravelmente agitadas, sua fala era muito interrompida e o corpo muito curvado e trêmulo. Ele caminhava quase inteiramente sobre a parte da frente dos pés, e teria caído a cada passo se não estivesse apoiado em sua bengala. Descreveu a doença como tendo aparecido gradualmente e como sendo, de acordo com sua total certeza, a consequência de irregularidades consideráveis em seu modo de vida e, particularmente, da sua indulgência com bebidas alcoólicas. Era morador de uma casa pobre em uma localidade distante, e estando totalmente certo da natureza incurável de sua doença, recusou qualquer tentativa de alívio.

\section{Caso III}

$\mathrm{O}$ caso a seguir também foi observado casualmente na rua. $\mathrm{O}$ paciente era um homem de cerca de 65 anos de idade, com uma constituição atlética notável. A agitação dos braços e pernas, e, aliás, da cabeça e de todo o corpo, era muito veemente para permitir que fosse chamada de tremor. Ele era completamente incapaz de caminhar; o corpo estava tão curvado e a cabeça tão jogada para frente que o obrigavam a seguir em uma corrida contínua, e a utilizar sua bengala a cada cinco ou seis passos para forçá-lo a ficar em uma postura mais ereta, projetando sua ponta com grande força contra o pavimento. Declarou que foi marinheiro e atribuiu seus problemas de saúde a ter ficado vários meses confinado em uma prisão na Espanha, onde se deitou, durante todo o período de seu confinamento, sobre a terra nua e úmida. A doença até então havia evoluído tanto e por tanto tempo que permitia pouca ou nenhuma perspectiva de alívio. Além disso, ele era um pobre mendigo, necessitando, além dos meios do experimento médico, aquelas ajudas colaterais que só seriam possíveis em um hospital. Recomendou-se, portanto, que ele participasse do experimento se algum alívio pudesse ser-lhe proporcionado daquele modo. O pobre homem, no entanto, não parecia de modo algum disposto a participar do experimento.

\section{Caso IV}

O próximo caso que se apresentou era de um cavalheiro de aproximadamente 55 anos, que havia sentido o tremor dos braços pela primeira vez cerca de cinco anos antes. Sua inscrição foi por conta de um grau considerável de inflamação sobre as costelas inferiores do lado esquerdo, que terminaram na formação de matéria sob a fáscia. Cerca de meio litro foi removido ao se fazer a abertura 


\section{CLÁSSICOS DA PSICOPATOLOGIA}

necessária, e uma quantidade considerável foi diariamente drenada por duas ou três semanas. Após sua recuperação, não parece ter havido nenhuma mudança em seu problema de saúde original. A oportunidade para conhecer sua evolução futura foi perdida devido à sua remoção para uma parte distante do país.

\section{Caso V}

Em outro caso, cujos detalhes não puderam ser obtidos, o cavalheiro, o paciente do caso em estado deplorável que apenas pode ser visto à distância, um dos sintomas característicos desta enfermidade, a incapacidade para a locomoção, exceto em ritmo de corrida, parecia estar presente em um grau extraordinário. Parecia ser necessário que tal cavalheiro fosse amparado por seu cuidador, em pé em frente a ele com uma mão apoiada em cada ombro, até que, com balanços leves para frente e para trás, ele estivesse em posição de equilíbrio; quando ele começava a correr, o cuidador deslizava e corria para frente, ficando pronto para recebê-lo e evitar sua queda, após o cavalheiro ter corrido cerca de vinte passos.

\section{Caso VI}

Em um caso que se apresentou para observação após os acima mencionados, todas as informações quanto à evolução da enfermidade foram prontamente obtidas. O cavalheiro que era o paciente do caso tinha 62 anos de idade. Ele levou uma vida de moderação e nunca foi exposto a qualquer situação ou circunstância em particular que pudesse considerar passível de ter ocasionado ou tê-lo disposto a esse problema de saúde; ele o considerava incidental à sua idade avançada, em vez de objeto de atenção médica. Ele, no entanto, se lembra de que há vinte anos, teve dores lombares, que foram graves e perduraram por algum tempo. Há 11 ou 12 anos, ou talvez mais, notou pela primeira vez fraqueza na mão e no braço esquerdos, e logo depois percebeu o início dos tremores. Em cerca de três anos após o incidente, o braço direito foi afetado de maneira similar, e logo em seguida os movimentos convulsivos afetaram todo o corpo e começaram a interromper a fala. Após cerca de três anos daquele momento as pernas foram afetadas. Nos últimos anos, a atividade dos intestinos foi muito prejudicada; e em dois ou três períodos diferentes, com grande dificuldade, eles funcionaram em situação de forte catarse. Entretanto, nos últimos 12 meses, esta dificuldade não tem sido tão grande; talvez devido ao aumento da secreção da mucosa que envolve as fezes, que precede e se segue à sua saída em quantidade considerável. 
Cerca de um ano depois, ao caminhar durante a noite, descobriu que tinha quase perdido o uso do lado direito, e que a face estava repuxada para o lado esquerdo. Seu atendente médico o viu no dia seguinte, quando o encontrou abatido, com uma pulsação fraca e rápida, sem dor de cabeça ou disposição para dormir. Portanto, nada mais foi feito além de promover a atividade dos intestinos e colocar um vesicatório na parte de trás do pescoço, e em aproximadamente duas semanas os membros haviam se recuperado inteiramente do seu estado de paralisia. Durante o tempo em que permaneceram nesse estado, nem o braço nem a perna do lado paralisado foram afetados pela agitação trêmula, mas quando o estado de paralisia foi removido, o tremor retornou.

Atualmente, ele é quase constantemente acometido de agitação, que descreve como geralmente se iniciando em um grau leve e aumentando gradualmente, até que atinja tal força a ponto de sacudir o quarto. Quando, através de uma mudança de postura súbita e algo violenta, ele é quase sempre capaz de interrompê-la. No entanto, logo após, ela começará em algum outro membro, em um grau pequeno, e crescerá gradualmente em violência, mas ele não se recorda de ter verificado se a isso se seguiu algum efeito prejudicial. Quando a agitação não era assim interrompida, declarou, ela gradualmente se expandia através de todos os membros e, por fim, afetava todo o tronco. Para ilustrar sua observação sobre o poder de interromper um movimento através de uma súbita mudança de postura, ele, tendo acabado de chegar de uma caminhada, com todos os membros sacudindo, jogou-se violentamente sobre uma cadeira e disse "Agora, eu estou tão bem quanto sempre estive em minha vida". Os tremores pararam completamente, mas retornaram em dois minutos.

Ele agora possuía pouco poder para dar a direção necessária para os movimentos de qualquer parte. Tinha pouca capacidade de se alimentar sozinho. Havia escrito de maneira pouco inteligível durante os últimos três anos e no momento não podia mais escrever. Seu cuidador observou que ultimamente os tremores algumas vezes começavam durante o sono e aumentavam até despertá-lo: quando ele sempre ficava em um estado de agitação e alerta.

Ao ser perguntado se caminhava com medo de cair, disse que sofria muito com isso; e respondeu afirmativamente à pergunta sobre se tinha qualquer dificuldade em evitar começar a correr. Foi perguntado se enquanto caminhava tinha muito medo da dificuldade de elevar seus pés, se visse uma pedra no caminho. Ele declarou, de maneira enfática, seu alarme em tais ocasiões, e sua esposa observou que ela acreditava que ao caminhar pelo quarto, ele considerava isso tão difícil quanto pisar em um alfinete.

Os casos anteriores parecem pertencer à mesma espécie: diferindo uns dos outros, talvez, apenas em quanto tempo a doença existia até então e a que estágio havia evoluído. 


\section{CLÁSSICOS DA PSICOPATOLOGIA}

\section{Capítulo II}

\section{Sintomas Patognômicos examinados - TRemor Coactus - SCELOTYRBE FESTINANS}

Observou-se na história anterior da doença, e nos casos acompanhados, que certas afecções, as agitações trêmulas, e a quase invencível propensão para correr, quando apenas se deseja andar, que foram consideradas pelos nosologistas como doenças distintas, mostraram-se sintomas patognomônicos desta enfermidade. Para determinar sob quais desses pontos de vista essas afecções deveriam ser consideradas, pareceu necessário fazer uma tentativa de examinar sua natureza e pesquisar as opiniões de autores anteriores em relação a elas.

$*$

$* \quad *$

I. Movimento trêmulo involuntário, com potência muscular voluntária reduzida, em partes, em inatividade, e mesmo com apoio.

É necessário que a natureza peculiar deste movimento trêmulo seja averiguada, para dar ao mesmo a designação apropriada, assim como para formar conjeturas prováveis quanto à natureza da enfermidade, que ele ajuda a caracterizar. Os tremores foram diferenciados por Juncker como Ativos, aqueles resultantes de súbita afecção da mente, como terror, raiva etc., e Passivos, dependentes de causas debilitantes, tais como idade avançada, paralisia etc. ${ }^{2}$ Uma distinção muito mais satisfatória e útil, porém, é feita por Sylvius de la Boë naqueles tremores que são produzidos por tentativas em movimento voluntário e aqueles que ocorrem enquanto o corpo está em descanso. ${ }^{3}$ Sauvages distingue

${ }^{2}$ Junckeri conspect. de tremore.

${ }^{3}$ Sect. V. Ubi autem solito pauciores deferunter ad eadem organa spiritus animales, imperfectæ ac imbecillæ observantur fieri eadem functiones, in motu tremulo et infirmo, nec diu durante, in visu debili, ac mox defatigato, \&c.

Sect. XIX. Inæqualiter, inordinatè, ac præter contraque voluntatem moventur spiritus animales per nervos ad partes mobiles, in motu convulsivo, ac tremore, quassuve membrorum coacto.

Distinguendus namque his tremor quiescente licet ac decumbente corpore molustus a motu tremulo, de quo dictum. Sect. V. Quique quiescente corpore cessat, eodemque iterum moto repetit.

Sect. XXV. Coactus tremor debetur animalibus spiritibus inordinatè ac continuo, cum aliquo impetu ad trementium membrorum musculos per nervos propulsis: sive fuerit is universalis, sive particularis, sive corpus fuerit ad huc robustum sive debile, Sylvii de la Boe. Prax. lib. i. cap. xlii. 
a última dessas espécies (Tremor Coactus) observando que as partes trêmulas saltam e vibram, mesmo quando apoiadas: entrementes, alguns tremores cessam, ele observa, quando o esforço voluntário para mover o membro para, ou a parte é apoiada, mas retornam quando queremos que o membro se movimente; de onde se supõe, ele diz, que o tremor é distinto de outros tipos de espasmo. ${ }^{4}$

Um pequeno grau de atenção será suficiente para perceber que Sauvages, por meio apenas dessa distinção, de fato separa esse tipo de movimento trêmulo e que é o tipo peculiar desta doença, do Genus Tremor. Ao fazê-lo, ele é totalmente justificado pela observação de Galen sobre o mesmo assunto, como observado por Van Swieten. "Binas has tremoris species ${ }^{6}$ Galenus subtiliter distinxit, atque etiam diversis nominibus insignivit, tremor enim $(\tau \delta o \mu \zeta)$ facultatis corpus moventis et vehentis infirmitate oboritur. Quippe nemo, qui artus movere non instituerit tremet. Palpitantes autem partes, etiam in quiete fuerint, etiamsi nullum illis motum induxeris palpitant. Ideo primam (posteriorem) modo descriptam tremoris speciem, quando quiescenti homini involuntariis illis et alternis motibus agitantur membra, palpitationem $(\pi \alpha \lambda \mu \mathrm{N})$ dixit, posteriorem (primam) vero, quæ non fit nisi homo conetur partes quasdam movere tremorem vocavit."

Com autoridade, o termo palpitação pode ser empregado para marcar aqueles movimentos mórbidos que caracterizam principalmente esta doença, não obstante este termo ter sido previsto por Sauvages como característica de outra espécie de tremor. $^{7}$ A separação entre a palpitação dos membros (Palmos de Galen, Tremor Coactus de de la Boë) e tremor é a que mais deve ser insistida, uma vez que a distinção pode ajudar a levar a um conhecimento sobre o centro da doença. Deve-se também ter em mente que essa afecção é distinguível de tremor

${ }^{4}$ Nosolog. Methodic. Auctore Fr. Boissier de Sauvages, Tomi. II. Partis ii. p. 54. 1763.

${ }^{5}$ Comment, in Herman. Boerhaav. Aphorismos. Tom. ii. p. 181.

${ }^{6}$ De tremore. Cap. 3 and 4. Chart, Tom. vii. p. 200-201.

${ }^{7}$ Sect. XVI. Tremor palpitans, Preysinger classis morborum. Palmos Galeni.

In tremoribus vulgaribus, æqualibus temporum intervallis, non musculus, sed artus ipsemet alternatim attollitur aut deprimitur, aut in oppositas partes it atque redit per minima tamen spatiola; in palpitatione verò sine ullo ordine musculi unius lacertus subito subsilit, nec regulariter continuoque movetur, sed nunc semel aut bis, nunc minimé intra idem tempus subsilit; an causa irritans in sensorio communi, an in musculo ipse palpitante Quærenda sit, ignoramus. Nosologice Methodicce, Vol. I. p. 559. 1768.

No entanto, o uso que Sauvages fez deste termo não será aqui considerado uma proibição absoluta do seu emprego. Uma vez que o tremor palpitans de Sauvages deve ser considerado mais uma palpitação dos músculos, enquanto o movimento que é um sintoma tão proeminente desta doença, pode ser considerado uma palpitação dos membros. 


\section{CLÁSSICOS DA PSICOPATOLOGIA}

pela agitação, no primeiro, que ocorre enquanto a parte afetada está apoiada e não está sendo utilizada, e também sendo interrompido pela adoção de movimento voluntário; enquanto o último, o tremor é imediatamente induzido ao colocar as partes em movimento. Sendo assim um artista, afligido pela enfermidade aqui tratada, enquanto sua mão e seu braço estão palpitando fortemente, agarrará seu pincel e seus movimentos serão suspensos, permitindo a ele utilizá-lo por um curto período. Mas, no tremor, se a mão estiver razoavelmente livre da afecção, se a caneta ou lápis for pego, os tremores começam imediatamente.

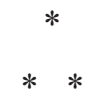

II. A propensão para curvar o tronco para frente e para passar do ritmo de caminhada ao de corrida.

Essa afecção, cuja observação parece autorizar a mesma ser considerada um sintoma peculiar desta doença, foi mencionada por alguns nosologistas: parece ter sido primeiro notada por Gaubius, que disse "Ocorrem casos nos quais os músculos devidamente estimulados para a atividade pelo impulso da vontade o fazem com uma agilidade espontânea e com um ímpeto que não deve ser reprimido, aceleram o seu movimento e correm perante à mente de má vontade. É uma falha frequente dos músculos pertencentes à fala; por outro lado, ainda sobre estes apenas: Vi um que era capaz de correr, mas não de falar."

Sauvages, referindo-se a esse sintoma, diz que outra doença que foi vista muito raramente por autores parece se referir ao mesmo gênero (Scelotyrbe, do qual ele torna Chorea sancti viti a primeira espécie); que, ele diz, "acho que não pode haver nome mais adequado do que Scelotyrbe aceleradora ou apressadora (Scelotyrbem festinantem, seu festiniam)".

Scelotyrbe festinans, ele diz, é uma espécie particular de scelotyrbe, na qual os pacientes, embora desejem caminhar do modo comum, são forçados a correr, que foi visto por Carguet e pelo ilustre Gaubius; uma afecção similar da fala, quando a língua assim ultrapassa a mente, é chamada de volubilidade. Mons. de Sauvages atribui esta queixa a uma carência de flexibilidade nas fibras musculares. Sendo assim, ele supõe que os pacientes dão passos menores e lutam

${ }^{8}$ Est et ubi musculi, recte quidem ad voluntatis nutum in actum concitati, injussa dein agilitate atque impetu non reprimendo motus suos accelerant, mentemque invitam præcurrunt. Vitium loquelæ musculis frequens, nec his solis tamen proprium: vidi enim, qui currere, non gradi, poterat*.

* Institution, Patholog. Medicinal. Auctore. H. D. Gaubio. 751. 
com um esforço ou ímpeto mais do que o normal para superar a resistência; caminhando com um passo rápido e acelerado, como se apressado contra a sua vontade. Chorea Viti, ele diz, ataca os jovens de ambos os sexos, mas esta doença apenas aqueles em idade avançada; e acrescenta que até agora ele viu apenas dois desses casos; e que não tem nada a oferecer a seu respeito, seja na teoria ou na

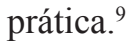

Tendo feito as pesquisas necessárias em relação a essas duas afecções, Tremor coactus de Sylvius de la Boë e de Sauvages, e Scelotyrbe festinans do último nosologista, que parecem ser sintomas característicos desta doença, torna-se necessário, como passo seguinte, empreender a distinção desta doença de outras que podem ter semelhança com a mesma em alguns aspectos particulares.

\section{Capítulo III}

\section{Paralisia Agitante diferenciada de outras doenÇas COM AS QUAIS PODE SER CONFUNDIDA}

Ao tratar de uma doença a partir de um conjunto de sintomas, alguns dos quais parecem não ter ainda chegado ao conhecimento geral dos profissionais,

${ }^{9}$ Ad idem genus morbi altera species rarissima ab auctoribus prætervisa referenda videtur, quam non aptius nominari posse putem quàm scelotyrbem festinantem, seu festiniam.

Sect. II. Scelotyrbe festinans: est peculiaris scelotyrbes species in qua ægri solito more dum gradi volunt currere coguntur, quod videre est apud D. Carquet, et observavit Leydæ illustr. Gaubius. Patholog. instit. 751, et in loquela hæc volubilitas dicitur quâ lingua præcurrit mentem. Video actu mulierem sexagenariam hoc affectam morbo siccitati nervorum tribuendo; laborat enim rheumatismo sicco, seu ab acrimonia sanguinis, dolores nocte a calore recrudescunt, à thermis non sublevantur: ei præscripsi phlebotomiam, et præmissis jusculis ex lactucâ, endiviâ, et collo arietis, lene catharticum, inde vero lacticinia.

Est affinitas cum scelotyrbe, chorea viti, deest flexibilitas in fibris musculorum; unde motus breves edunt, et conatu seu impetu solito majori, cum resistentiam illam superare nituntur, velut inviti festinant, ac præcipiti seu concitato passu gradiuntur. Chorea viti pueros, puellasve impuberes aggreditur; festinia vero senes, et duos tantum hactenus observare mihi contigit. Quam multos autem videmus morbos, paucissimosque observamus. De theoria et pràxi nihil habeo quod dicam; etenim sola experienta praxin cujusvis morbi determinat, et ex hac pro felici vel infausto successu theoria dein elicienda est. Nosolog. Methodic. Auctore Fr. Boissier de Sauvages. Tomi. II. Part ii. p. 108. 


\section{CLÁSSICOS DA PSICOPATOLOGIA}

é necessário ter um cuidado especial ao tentar marcar suas características diagnósticas. É suficiente, em geral, apontar as diferenças características que são observáveis entre doenças que se parecem, em alguns aspectos, umas com as outras. No entanto, neste caso, mais é necessário: é necessário mostrar que se trata de uma doença que não está de acordo com nenhuma outra que está marcada nos arranjos sistemáticos dos nosologistas; e que o nome pelo qual ela é aqui distinguida foi até agora vagamente aplicado a doenças muito diferentes umas das outras, assim como daquela da qual é agora apropriado.

Paralisia, seja como consequência da compressão do cérebro ou dependente da exaustão parcial da energia do órgão, pode, quando os membros paralisados são afetados por movimentos trêmulos, ser confundida com esta doença. Nesses casos, a abolição ou diminuição da ação muscular voluntária ocorre subitamente, e a capacidade de sentir algumas vezes também fica prejudicada. Mas, nesta doença, a diminuição da influência da vontade sobre os músculos ocorre muito lentamente, é sempre acompanhada, e até mesmo precedida, por agitações das partes afetadas, e nunca por uma capacidade de sentir reduzida. Os ditados da vontade são até mesmo nos estágios finais da doença transmitidos aos músculos; e os músculos atuam no impulso, mas suas ações são distorcidas.

Casos anômalos de afecções convulsivas foram designados com o termo paralisia agitante: um termo que parece ser impropriamente aplicado a esses casos, independentemente da falta de concordância entre tais casos e a doença que aqui foi designada como paralisia agitante. Dr. Kirkland, em seu comentário sobre as Afecções Apopléticas e Paralíticas etc., menciona o seguinte caso, relacionado pelo dr. Charlton como pertencendo, ele diz, à classe das paralisias agitantes. "Mary Ford, de constituição sanguínea e robusta, teve um movimento involuntário de seu braço direito, ocasionado por um susto, que primeiro causaram espasmos convulsivos e uma dor lancinante no estômago, que desapareceram subitamente, e seu braço direito foi instantaneamente lançado em um movimento involuntário e perpétuo, como o balanço de um pêndulo, elevando a mão a cada vibração mais alto do que sua cabeça, mas, se por qualquer razão o movimento era interrompido, a dor de estômago voltava e os espasmos convulsivos eram a consequência certa, que terminavam quando a vibração de sua mão retornava".

Outro caso, que o doutor designa de 'Uma paralisia agitante', aparentemente causada por vermes, assim descrita: "Um pobre menino, cerca de 12 ou 13 anos de idade, foi acometido por uma paralisia agitante. Suas pernas se tornaram inúteis e, juntamente com sua cabeça e mãos, ficaram em uma agitação contínua; após muitas semanas tentando vários remédios, a minha assistência foi solicitada.

Tendo seus intestinos sido limpos, receitei a ele um grão de ópio por dia no comprimido; e em três ou quatro dias a agitação tinha quase completamente o 
deixado". Seguindo este plano, o remédio provou ser um vermífugo, e logo ele pôde andar e teve a saúde perfeita restaurada.

É necessário aqui determinar se esses casos podem ou não ser classificados como paralisia agitante; como, se eles forem adequadamente classificados, os casos que foram descritos nas páginas anteriores diferem tanto destes para certamente haver uma oposição quanto a serem classificados juntos: e a doença, que é objeto destas páginas, não pode ser considerada a mesma com paralisia agitante, como caracterizada por aqueles casos.

O termo paralisia agitante é evidentemente inaplicável ao primeiro desses casos, que parece pertencer mais propriamente ao gênero Convulsio, de Cullen, ou ao Hieranosos de Linnæus e Vogel. ${ }^{10}$

$\mathrm{O}$ último parece se referir àquela classe de formas proteales da doença, geradas por um estado desordenado de via direta, simpaticamente afetando a influência nervosa em uma parte distante do corpo.

A menos que seja dada atenção a uma circunstância, esta doença será confundida com aquelas espécies de tremores passivos às quais o termo paralisia agitante tem sido frequentemente aplicado. Esses são, tremor temulentus, os tremores consequentes da indulgência em consumir bebidas alcoólicas; aqueles que procedem do emprego não moderado de chá e café; que parece depender da idade avançada; e todos os tremores que procedem de várias circunstâncias que induzem à diminuição da potência no sistema nervoso. No entanto, prestando atenção apenas naquela circunstância, que já foi notada como característica do mero tremor, a distinção será logo feita. Se o membro que treme for apoiado,

${ }^{10}$ Corporis agitatio continua, indolens, convulsiva, cum sensibilitate.-Linn.

Agitatio corporis vel artuum convulsiva continua, chronica, cum integritate sensuum.-Vogel.

Este gênero é resolvido por Cullen como sendo da Convulsão. Synops. Nosol. 1803.

Dr. Macbride forneceu um caso muito interessante e ilustrativo desta doença.

"Hieranasos ou Morbus Sacer, assim chamado, vulgar e supostamente resultante de bruxaria, ou de alguma influência celestial extraordinária, é um gênero diferente de doença, embora muito incomum; o autor uma vez teve uma oportunidade para ver um caso. O paciente era um jovem de cerca de 17 anos, que no momento já estava lutando contra esta doença extraordinária há mais de 12 anos. Seu corpo estava tão distorcido e as pernas e os braços tão torcidos a seu redor, pela contínua ação convulsiva, que nenhuma palavra pode descrever adequadamente a estranheza de sua figura; a agitação dos músculos era perpétua, mas, em geral, ele não reclamava de dor ou enjoo; e seus sentidos estavam mantidos em perfeito estado, tanto que ele costumava ajudar a sua mãe, que mantinha uma pequena escola, a ensinar as crianças a ler." A methodical Introduction to the Theory and Practice of Physic. By David Macbride, M.D. p. 559. 


\section{CLÁSSICOS DA PSICOPATOLOGIA}

e nenhum de seus músculos for colocado em ação, os tremores cessarão. $\mathrm{Na}$ paralisia agitante real, o contrário disso ocorre: a agitação continua com força total, embora o membro esteja em descanso e não esteja sendo empregado; e, algumas vezes, diminui ao iniciar-se o emprego dos músculos.

\section{Capítulo IV}

\section{Causa imediata - Causas remotas - Casos Ilustrativos}

Antes de fazer qualquer tentativa de apontar a natureza e a causa desta doença, é necessário alegar que isso é feito em circunstâncias muito desfavoráveis. Sem a ajuda de investigações anteriores imediatamente direcionadas a esta doença, e não tendo tido a vantagem, em um único caso, daquela luz que o exame anatômico propicia, apenas opiniões e não fatos podem ser oferecidos. A conjetura encontrada na analogia e uma consideração atenta dos sintomas peculiares da doença foram os únicos guias que puderam ser obtidos para esta pesquisa, cujo resultado é, e deve ser, oferecido com hesitação.

\section{SuPosta CAUSA IMEdiata}

Um estado enfermo da medula espinhal, naquela parte que está contida no canal, formada pela vértebra cervical superior, e se estendendo conforme a doença avança para a medula oblongata.

Pela natureza dos sintomas, aprendemos que a doença depende de alguma irregularidade na direção da influência do nervo; pela grande variedade de partes afetadas, que o prejuízo ocorre na fonte dessa influência em vez de meramente nos nervos das partes; pela situação das partes cujas ações são prejudicadas e pela ordem na qual elas são afetadas, que a causa imediata da doença está na parte superior da medula espinhal; e pela ausência de qualquer prejuízo aos sentidos e ao intelecto, que o estado mórbido não se estende ao encéfalo.

Existindo incerteza quando à natureza da causa imediata desta doença, as suas causas remotas devem ser necessariamente mencionadas com indecisão. Pressupondo-se, no entanto, o estado que acabou de ser mencionado como a causa imediata, pode-se concluir que isso pode ser o resultado de prejuízos na própria medula ou na teca que ajuda a formar o canal na qual está inserida. 
O grande grau de mobilidade naquela porção da espinha que é formada pela vértebra cervical superior pode torná-la, e as partes contidas, passível a ferimento devido a contorções súbitas. Consequentemente, portanto, pode se seguir uma inflamação de progressão mais rápida ou mais lenta, doença da vértebra, desarranjo da estrutura na medula ou em suas membranas, espessamento ou até mesmo ulceração da teca, efusão de fluidos etc.

Mas, em nenhum caso que foi observado, o paciente se lembrou de ter tido um ferimento desse tipo, ou qualquer dor fixa anteriormente nessas partes, que possa ter levado à opinião de que a base dessa enfermidade estivesse assim estabelecida. Sobre a questão das causas remotas, não foram obtidos ainda relatos satisfatórios de qualquer dos sofredores. Embora uma pessoa tenha atribuído esta aflição à indulgência às bebidas alcoólicas e outra a deitar por longo tempo sobre o chão úmido; as outras foram incapazes de sugerir qualquer circunstância que, em sua opinião, possa ser considerada como dando origem, ou tendo disposto, à calamidade que sofriam.

Os casos ilustrativos da natureza e da causa desta enfermidade são muito raros. No próximo caso, sintomas muito similares foram observados, na medida em que afetavam as extremidades inferiores. Não se deve duvidar de que a medula espinhal foi aqui afetada, em sua parte inferior, mas isso, infelizmente, nunca foi averiguado por meio de exame. Deve-se, no entanto, notar que este caso diferiu daqueles que foram expostos desta doença, no súbito aparecimento dos sintomas.

A. B. com a idade de 26 anos, durante a administração de mercúrio para uma afecção venérea, foi exposto a um clima severamente inclemente, por muitas horas, e na manhã seguinte reclamou de dor extrema nas costas, e da total incapacidade para empregar voluntariamente os músculos das extremidades inferiores, que ficaram continuamente agitadas com graves movimentos convulsivos. $\mathrm{O}$ médico que o atendeu empregou aqueles meios que pareciam os melhores para aliviá-lo, porém, sem efeito benéfico. As extremidades inferiores estavam em contínua agitação com fortes movimentos palpitantes e, frequentemente, três ou quatro vezes em um minuto, subitamente se elevando com grande veemência dois ou três pés do chão, na direção frontal ou oblíqua, batendo um membro contra o outro, ou contra as cadeiras, mesas ou qualquer substância que estivesse no caminho. Para parar esses movimentos desordenados, nada foi efetivo, exceto golpear as coxas com força durante as convulsões mais violentas. Não foi obtida nenhuma vantagem de nenhum dos meios que foram empregados durante os 12 meses seguintes. Dez anos inteiros após esse período, o infeliz objeto desta enfermidade foi encontrado na rua, deslocando-se sozinho sentado em uma cadeira; os movimentos convulsivos haviam cessado, e os membros se tornaram totalmente inertes e insensíveis a qualquer impulso da vontade. 


\section{CLÁSSICOS DA PSICOPATOLOGIA}

Deve-se reconhecer que, nos casos bem conhecidos descritos pelo sr. Potts, desse tipo de paralisia dos membros inferiores que é frequentemente encontrado acompanhando a curvatura da espinha, e onde existe um estado cariado da vértebra, nenhuma analogia instrutiva foi descoberta; leves movimentos convulsivos podem, de fato, ocorrer na doença procedente da curvatura da espinha, mas movimentos palpitantes dos membros, tais como os pertencentes à doença aqui descrita, não parecem ter sido até agora observados.

Enquanto batalho para determinar a natureza e a origem desta doença, tornou-se necessário dar os seguintes detalhes de um caso interessante de paralisia ocasionada por uma queda, acompanhada de sintomas incomuns, relatada pelo dr. Maty, no terceiro volume de Observações e Pesquisas Médicas. O paciente deste caso, o Conde de Lordat, teve a infelicidade de cair de um barranco muito alto e inclinado. Sua cabeça foi arremessada contra o alto de uma carruagem e curvou-se da esquerda para a direita; seu ombro, braço e especialmente sua mão esquerda tiveram uma contusão considerável. De início, ele sentiu muita dor ao longo do lado esquerdo do seu pescoço, mas não teve, naquele momento ou depois, qualquer desmaio, vômito ou vertigem. No sexto dia, ele verteu sangue, por conta da dor no seu ombro e da contusão na sua mão, que foi então o único sintoma do qual reclamou e do qual logo se viu livre. Próximo ao início do inverno seguinte, ele começou a sentir uma pequena dificuldade em pronunciar algumas palavras e seu braço esquerdo ficou mais fraco. Na primavera seguinte, tendo sofrido consideravelmente do inverno severo, achou que as dificuldades em falar e em mover seu braço esquerdo tinham aumentado consideravelmente. Ao utilizar as águas termais de Bourbonne, sua fala ficou mais desenvolta, mas em seu retorno a Paris, a paralisia havia aumentado e o braço ficou inutilizado. No início da primavera seguinte, ele foi a Balaruc, quando foi afetado por movimentos convulsivos involuntários em todo o seu corpo. O braço esquerdo murchou cada vez mais, começou a cuspir, e agora pronunciava algumas palavras com muita dificuldade. Fricções e sinapismos foram sucessivamente tentados, e foi feita uma abertura com material cáustico e mantida aberta por algum tempo sem qualquer efeito, mas não é feita menção sobre em que parte a abertura foi feita.

Logo após esse fato, e três anos e meio após a queda, o dr. Maty viu o paciente pela primeira vez e dá a seguinte descrição da sua situação. "O paciente mais melancólico que eu já observei. O paciente, naturalmente um belo homem, de estatura média, sanguíneo, de disposição alegre e mente ativa, parecia macilento, inclinado e abatido. Ele ainda caminhava sozinho com uma bengala, de um cômodo a outro, mas com grande dificuldade e de maneira cambaleante. Sua mão e seu braço esquerdos haviam se reduzido e dificilmente realizavam qualquer movimento. $O$ direito estava em torpor e ele dificilmente conseguia 
elevá-lo até sua cabeça. Sua saliva escorria continuamente de sua boca e ele não conseguia retê-la nem cuspi-la para longe. As palavras que ele ainda conseguia pronunciar eram monossilábicas, e saíam, após muito esforço, em uma expiração violenta, e em uma voz tão baixa e com a articulação tão indistinta que era muito difícil compreendê-las, a não ser aqueles que conviviam com ele. Ele conseguia respirar com muita dificuldade, sua pulsação era fraca, porém não acelerada nem intermitente. Conseguia se alimentar muito pouco, não podendo mastigar nem engolir sólidos, e até mesmo sentindo muita dor ao engolir líquidos. O leite era quase seu único alimento; seu corpo estava muito frouxo; sua urina natural; seu sono bom, seus sentidos e poderes da mente não estavam prejudicados; ele prestava atenção, era sensível a tudo o que era dito na conversa e se mostrava muito interessando em participar. Mas era continuamente contido pela dificuldade de sua fala e pela dificuldade imposta a seus ouvintes. Felizmente, para ele, era capaz de ler e até mesmo de escrever, como me mostrou, colocando em minhas mãos um relato de sua situação atual que ele mesmo elaborou; e fui informado que ele gastou todo o seu tempo escrevendo sobre os mais tortuosos assuntos."

Esse cavalheiro faleceu cerca de quatro anos após o acidente, quando o corpo foi examinado pelo dr. Bellett e pelo Mons. Sorbier, que fizeram o seguinte relato:

"Primeiro examinamos os músculos da língua, que estavam afinados e com uma textura frouxa. Não observamos nenhum sinal de compressão nos nervos linguais ou braquiais, no alto de sua saída da base do crânio e da vértebra do pescoço; mas eles nos pareceram mais compactos do que normalmente são, estando quase tendinosos A dura-máter estava em estado sólido, porém a pia-máter estava cheia de sangue e linfa; nela, várias hidátides, e em direção às fauces, algumas marcas de supuração foram observadas. Os ventrículos estavam cheios de água e o plexo coroide estava consideravelmente aumentado e cheio de sangue coagulado. A superfície cortical do cérebro pareceu mais marrom do que o habitual, mas a parte medular ou o cerebelo não estavam prejudicados. Notamos principalmente a medula oblongata, que estava muito aumentada, ultrapassando o tamanho normal em mais de um terço. Do mesmo modo, estava mais compacta. As membranas, que na sua continuação incluíam a medula espinhal, estavam tão duras que foi muito difícil cortá-las, e observamos que esta era a causa da textura tendinosa dos nervos cervicais. A medula tinha se tornado tão sólida que não se deformava sob a pressão de nossos dedos, resistindo como um corpo caloso, e não ficando com hematoma. Essa dureza foi observada em toda a extensão da vértebra do pescoço, e diminuía em graus, e não era nem de perto tão considerável na vértebra do tórax. Embora o paciente tivesse apenas trinta anos de idade, as cartilagens do esterno estavam ossificadas e demandaram muito trabalho para cortá-las, como embaixo das costelas; como aquelas, as costelas estavam esponjosas, porém mais brancas. Os pulmões e o coração estavam firmes. No 


\section{CLÁSSICOS DA PSICOPATOLOGIA}

fundo do estômago havia uma inflamação, que aumentava à medida que se estendia aos intestinos. O íleo tinha tonalidade escura e lívida, o que é observado em partes membranosas tendendo à mortificação. $\mathrm{O}$ cólon não tinha mais do que uma polegada de diâmetro, o reto era ainda pequeno, mas ambos pareciam firmes. A partir dessas aparências, não tínhamos dúvida em fixar a causa da paralisia gradual na alteração da medula espinhal e da oblongata."

Dr. Bellett oferece a seguinte explanação para estas mudanças. "Imagino que, por meio desse acidente, com a cabeça violentamente curvada para a direita, as membranas dos nervos do lado esquerdo foram excessivamente alongadas e irritadas; que esta causa se estendeu em graus para a medula espinhal, que sendo assim comprimida, fez surgir os sintomas de paralisia, não apenas no braço esquerdo, mas em alguma medida também no braço direito. Este endurecimento parece ter sido ocasionado pelo afluxo constante de sucos nutritivos, que pararam naquele lugar e foram privados da maioria das suas partes líquidas; os mais grossos incapazes de se espalhar na cavidade do osso, onde ficaram confinados, puderam apenas adquirir maior solidez, e transformaram um corpo macio em uma massa dura e quase óssea. Esse relato similar do aumento da medula oblongata, que ao ser carregada com mais sucos do que era capaz de enviar, inchou da mesma maneira que os galhos de uma árvore, que cresce a um tamanho monstruoso, quando a seiva que corre dentro deles para de avançar. A medula oblongata não ter crescido tanto como a espinhal se deve, sem dúvida, ao fato de não ficar confinada em uma teca óssea, mas circundada por partes macias, que permitiu a ela espaço para se espalhar. A obstrução por parte da massa desta substância deve ter afetado o cérebro, e provavelmente induziu o espessamento da pia-máter, as hidátides, e o começo da supuração, enquanto a dura-máter, tendo uma textura mais dura, não foi prejudicada." 11

Em alguns dos sintomas que apareceram neste caso, observa-se uma concordância entre ele e aqueles casos que foram mencionados no começo destas páginas. $\mathrm{O}$ estado enfraquecido de ambos os braços; a força diminuindo primeiro em um braço e, então, de maneira similar no outro braço; a afecção da fala; a dificuldade em mastigar e engolir, bem como em reter ou liberar livremente a saliva; os movimentos convulsivos do corpo e o estado sem prejuízo do intelecto; constituem tal grau de concordância que, embora não possa marcar uma identidade da doença, servem pelo menos para mostrar que quase as mesmas partes foram o lugar da doença em ambas as instâncias. Assim, atingimos alguma coisa como uma confirmação da suposta causa imediata e uma das pressupostas causas ocasionais.

${ }^{11}$ Medical Observations and Inquiries, Vol. III. p. 257. 
Ao conjeturar sobre a causa desta doença, as seguintes observações coletadas sobre os efeitos de um ferimento na medula espinhal, por Sir Everard Home, mereceram atenção particular. A partir delas, verificou-se que nenhum dos sintomas característicos desta enfermidade é produzido por compressão, laceração ou divisão completa da medula espinhal.

"A pressão na medula espinhal do pescoço, pelo sangue coagulado, produziu afecções paralíticas dos braços e das pernas; todas as funções dos órgãos internos foram realizadas por 35 dias, mas a urina e as fezes passavam involuntariamente". 12

"O sangue extravasado na parte central da medula, no pescoço, foi acompanhado de uma afecção paralítica das pernas, mas não dos braços". ${ }^{13}$

"Em um caso em que a substância da medula foi lacerada no pescoço, houve uma paralisia em todas as partes abaixo da laceração, o revestimento do esôfago tendo ficado tão sensível, que sólidos não podiam ser engolidos, tamanha a dor que ocasionavam". ${ }^{14}$

"Quando a medula das costas foi completamente dividida, houve perda momentânea da visão, perda da memória por 15 minutos e insensibilidade permanente em todas as partes inferiores do corpo. A pele acima da divisão da medula espinhal transpirava, a abaixo, não. A medula espinhal ferida parecia estar extremamente sensível". ${ }^{15}$ Philosophical Transactions, 1816, p. 485.

Em dois dos casos já observados, os sintomas de reumatismo já existiam anteriormente; e no Caso IV, há o relato de que o braço direito, onde a palpitação começou, foi muito violentamente afetado por dor reumática nas extremidades dos dedos. A consideração deste caso, onde a palpitação foi precedida, com muita antecedência, por essa dolorosa afecção do braço, levou à suposição de que esta última circunstância pode ser a causa das palpitações e dos outros sintomas subsequentes desta doença. Essa suposição levou naturalmente a uma grande atenção sobre o caso seguinte; e obviamente influenciou o modo do tratamento que foi adotado.

${ }^{12}$ Um coágulo de sangue, o espessamento de uma coroa, foi encontrado sobre a superfície externa da dura-máter que cobre a medula espinhal, estendendo-se da quarta vértebra do pescoço à segunda vértebra dorsal. A medula espinhal em si não estava prejudicada.

${ }^{13}$ A sexta e sétima vértebras do pescoço estavam descoladas, a medula espinhal, externamente, não estava prejudicada, mas no centro de sua substância, justo naquela parte, havia um coágulo de sangue com quase duas polegadas de comprimento.

${ }^{14}$ A sétima vértebra do pescoço foi fraturada, e a medula espinhal que passa por ela foi lacerada e comprimida.

${ }^{15}$ A medula espinhal, dentro do canal da sexta vértebra dorsal, foi completamente destruída por uma bala de mosquete. A pessoa viveu por quatro dias. 


\section{CLÁSSICOS DA PSICOPATOLOGIA}

A. B. objeto de uma afecção reumática do músculo deltoide, sentiu os inconvenientes normais da mesma por dois ou três dias. Mas, à noite, descobriu que a dor havia se estendido para baixo no braço, ao longo da parte anterior do antebraço e nas laterais dos dedos, onde sentia um formigamento constante. A dor, sem ser extremamente intensa, podia, no entanto, impedir o sono: e parecia seguir o curso do nervo braquial. Ao averiguar a propriedade dessa conclusão, a dor se ramificou para a parte anterior e posterior do peito, e aumentava levemente ao se respirar profundamente.

Essas circunstâncias sugeriram a probabilidade de uma leve inflamação ou aumentaram a determinação na origem dos nervos dessas partes, e na vizinhança da medula. Com base nisso, foi removido sangue da parte posterior do pescoço, por meio de escavação; aplicações quentes foram feitas por cerca de uma hora, quando a parte superior posterior do pescoço foi coberta por um vesicatório, a transpiração foi livremente induzida por duas ou três doses pequenas de antimônio e na manhã seguinte os intestinos foram evacuados por meio de uma dose apropriada de calomel (cloreto de mercúrio). No dia seguinte, as dores diminuíram bastante, e no curso de quatro ou cinco dias tinham quase desaparecido. O braço e a mão estavam então mais pesados do que o normal e estavam evidentemente muito enfraquecidos: doendo e se sentindo muito desgastados após o menor esforço. A força do braço não foi completamente recuperada no final de mais de 12 meses; e, após mais do que o dobro desse tempo, o esforço suscitava o sentimento de desgaste doloroso, mas nenhuma palpitação ou outro sintoma desagradável ocorreu durante cinco ou seis anos que se passaram.

O início, progresso e término desse ataque, com o sucesso acompanhando o modo do tratamento e os sintomas que se seguiram, parecem levar à conjetura de que a causa imediata da doença, neste caso, existia na medula espinhal e que ela pode, se negligenciada, gradualmente evoluir para a doença, que é objeto da presente investigação.

Alguns poucos meses após a ocorrência do caso anterior, o autor destas linhas foi chamado a atender uma mulher de cerca de quarenta anos de idade, reclamando de muita dor em ambos os braços, se estendendo do ombro até a ponta dos dedos. Ela declarou ter sido atacada do mesmo modo descrito no caso anterior, cerca de nove meses antes, que a queixa foi considerada um reumatismo e que não se beneficiou de nenhuma medicação que foi empregada, mas que, após três ou quatro semanas, ela se alterou gradualmente deixando ambos os braços e mãos em um estado muito enfraquecido e trêmulo. Eles de algum modo se recuperaram desse estado, mas ela ficou extremamente ansiosa com medo de que se o presente ataque não fosse logo controlado, ela poderia perder inteiramente o uso das mãos e dos braços.

Instruído pelo caso anterior, os meios similares foram recomendados aqui. Sanguessugas, aplicações estimulantes e um vesicatório, que foi feito por algum 
tempo para controlar uma secreção purulenta, foram aplicados sobre a vértebra cervical; e no curso de alguns poucos dias, a dor foi totalmente removida. É uma pena que nenhuma informação adicional, sobre o progresso deste caso, pôde ser obtida.

Ao me deparar com esses dois casos, pensei que não seria improvável que os ataques desse tipo, considerados à época meramente afecções reumáticas, pudesse ser a base desta lamentável doença, que pode se manifestar em algum período distante, quando a circunstância na qual foi originada tinha, talvez, quase escapado da memória. De fato, quando se considera que nem nos casos comuns de paralisia das extremidades inferiores, originários de espinha doente, nem nos casos de medula ferida por vértebra fraturada, nenhum dos sintomas peculiares desta doença são observáveis, nós necessariamente duvidamos da probabilidade de ela ser o efeito direto de qualquer ferimento súbito. No entanto, levando todas as circunstâncias em devida consideração, particularmente a maneira muito gradual na qual a doença começa, e procede em seu ataque, bem como a incapacidade de atribuir a sua origem a qualquer causa mais óbvia, somos levados a buscar por ela em alguma alteração mórbida lenta na estrutura da medula, ou em suas membranas circundantes, ou na teca, ocasionada por uma simples inflamação ou afecção reumática ou estrófula.

Deve ser muito óbvio que a evidência produzida quanto à natureza das causas aproximadas e ocasionais desta doença não é de modo algum conclusiva. Portanto, uma alusão ao teste que será produzido por um exame de alguns dos mais proeminentes sintomas, especialmente quanto à sua concordância com a suposta causa imediata, é mais particularmente necessária. Satisfeito com a importância desta parte do presente empreendimento, nenhuma apologia é oferecida para a medida na qual o exame é realizado.

Se a palpitação e a fraqueza que acompanham os membros etc., forem consideradas como sendo a ordem na qual as várias partes são atacadas, acredita-se que alguma confirmação será obtida em relação à opinião que acabou de ser oferecida, quanto à causa, ou pelo menos o lugar, daquela mudança que pode ser considerada a causa imediata desta doença.

Um dos braços, em todos os casos que foram aqui mencionados, foi a parte na qual os sintomas foram primeiro percebidos; as pernas, a cabeça e o tronco foram então gradualmente afetados, e, por último, os músculos da boca e das fauces sucumbiram à influência mórbida.

Os braços, as partes que primeiro manifestaram a ação desordenada, obviamente nos guiaram enquanto buscávamos a causa dessas mudanças nos nervos braquiais. No entanto, ao encontrar o problema se estendendo para outras partes, não supridas por estes, mas com outros nervos derivados de quase a mesma parte da medula espinhal, obviamente fomos levados a considerar aquela porção da 


\section{CLÁSSICOS DA PSICOPATOLOGIA}

medula espinhal em si, de onde os nervos são derivados, como a parte na qual aquelas mudanças ocorreram, que constituem a causa imediata desta doença.

A partir da posterior afecção das extremidades inferiores, e da falha de força nos músculos do tronco, pode-se inferir tal mudança na substância da medula espinhal, como tendo interrompido consideravelmente e interferido com a extensão da influência dos nervos naquelas partes, cujos nervos são derivados de qualquer porção da medula abaixo da parte que passou pela mudança causada pela doença.

A dificuldade em manter o tronco ereto, bem como a propensão em adotar um passo apressado, é também atribuível à diminuição da potência nervosa nos músculos extensores da cabeça e do tronco, já que impede que eles realizem o ofício de manter a cabeça e o corpo em uma posição ereta.

Do impedimento da fala, da dificuldade de mastigar e engolir, da incapacidade de reter ou livremente ejetar a saliva, pode-se com propriedade inferir a extensão da mudança mórbida para cima através da medula espinhal à medula oblongata, necessariamente prejudicando a potência de vários nervos derivados daquela porção à qual a mudança mórbida possa ter alcançado. Na ocorrência tardia deste conjunto de sintomas e na extensão para cima do estado mórbido, pode-se observar uma concordância muito estreita entre esta doença e aquela que já foi mostrada, que se mostrou fatal para o Conde de Lordat. Mas, nesse caso, a doença sem dúvida se tornou diferentemente modificada e seus sintomas se aceleraram consideravelmente em consequência da magnitude do ferimento pelo qual a doença foi induzida.

\section{Capítulo V}

\section{Considerações Quanto aOs Meios de CURA}

As investigações feitas nas páginas anteriores produziram, o que deve ser lamentado, apenas um pouco mais do que evidência da inferência: nada direto e satisfatório foi obtido. Tudo o que se aventurou assumir-se aqui foi que a doença depende de um estado desordenado da parte da medula que está contida na vértebra cervical. Mas qual é a natureza da mudança mórbida, e se ela se origina na própria medula, em suas membranas ou na teca que a contém, são, no momento, o objeto de dúvida e conjetura. No entanto, embora no momento haja incerteza quanto à natureza precisa da doença, ainda não se pode considerá-la uma doença para a qual não existe remédio.

Pelo contrário, parece haver razão suficiente para esperar que algum processo terapêutico seja logo descoberto pelo qual, pelo menos, a progressão da doença possa ser interrompida. Raramente acontece de a agitação se estender 
além dos braços nos dois primeiros anos; esse período, portanto, se estivermos dispostos a dividir a doença em estágios, poderia compreender o primeiro estágio. Nesse período, é muito provável que os meios terapêuticos possam ser empregados com sucesso; e até mesmo, se infelizmente adiado a um período posterior, poderão deter o progresso posterior da doença, embora seja difícil esperar que os efeitos já produzidos sejam removidos.

Por meio da análise das mudanças que ocorreram no caso do Conde de Lordat, parece que fomos capazes de traçar a ordem e o modo no qual as mudanças mórbidas podem proceder nesta doença. A partir de qualquer causa ocasional, o ligamento tecal, as membranas ou a medula em si podem passar para um estado de simples excitação ou irritação, que pode ser gradualmente sucedido por um afluxo local e a determinação de sangue nos vasos sanguíneos, que pode terminar em inflamação real, mas lenta. $\mathrm{O}$ resultado disso seria um espessamento da teca, ou das membranas e, talvez, um aumento no volume da medula em si, que gradualmente ocasionaria tal grau de pressão contra as laterais do canal inflexível, que deve por fim interceptar a influência do cérebro na porção inferior da coluna medular e nas partes nas quais os nervos desta porção estão dispostos.

A partir dessa análise, e pressupondo-se que as mudanças mórbidas nesta doença podem não ser tão diferentes daquelas ocorridas no caso do Conde de Lordat, a possibilidade de alívio a partir do modo de tratamento proposto parece ser suficiente para garantir o seu teste.

Em tal caso, pois, em qualquer período da doença em que se proponha uma tentativa de cura, o sangue deve ser primeiro retirado da parte superior do pescoço, a menos que contraindicado por qualquer circunstância em particular. Após o que, vesicatórios devem ser aplicados a tal parte, além de se obter uma secreção purulenta por meio do uso apropriado do óleo de Sabine. Se os vesicatórios forem considerados muito inconvenientes ou se não for obtida uma quantidade suficiente de secreção por meio deles, uma abertura de pelo menos uma polegada e meia de comprimento deve ser feita em cada lado da coluna vertebral, em sua parte superior. Estas, presume-se, seriam melhor formadas por uma substância cáustica e mantidas abertas por qualquer substância adequada. ${ }^{16}$

Poderia se imaginar que tal benefício considerável, de fato, que tais curas impressionantes poderiam ter sido efetuadas por aberturas nos casos de paralisia

${ }^{16}$ A Cortiça, que foi até agora negligenciada, parece ser muito apropriada para este fim. Ela tem leveza, maciez, elasticidade e firmeza suficiente; e também é capaz de ser facilmente moldada em qualquer forma conveniente. A forma que seria mais bem adaptada para a parte, a de uma amêndoa ou da variedade de feijão chamada de feijão-da-espanha, mas, pelo menos, uma polegada e meia de comprimento. 


\section{CLÁSSICOS DA PSICOPATOLOGIA}

das extremidades inferiores da espinha doente? Embora satisfeito com a atribuição desses casos à ação de estrófulos, estamos de fato muito pouco informados em relação à natureza da afecção, induzindo o estado cariado da vértebra, assim como estamos em relação à mudança peculiar da estrutura que acontece nesta doença. Também estamos igualmente desinformados sobre o tipo peculiar de ação mórbida que ocorre nos ligamentos das juntas, bem como sobre o que ocorre em diferentes instâncias de dores e afecções profundamente assentadas das partes contidas na cabeça, tórax e abdômen, e em todos os casos em que a indução de uma secreção purulenta na sua vizinhança tão frequentemente produz uma cura. Ainda não foi realizado nenhum experimento para provar, mas a analogia certamente assegura a esperança, que vantagens similares podem ser derivadas do uso dos meios enumerados, na presente doença. É óbvio que a chance de obter alívio dependerá em grande medida do período no qual os meios sejam empregados. Como em qualquer outra doença, aqui também, quanto mais rápido os remédios forem utilizados, maior será a probabilidade de sucesso. No entanto, nesta doença, há uma circunstância que demanda atenção particular: o longo período pelo qual ela pode se estender. Um de seus sintomas peculiares, Scelotyrbe festinans, pode não ocorrer mesmo que a doença já exista por dez ou 12 anos, ou mais. Sendo assim, quando procuramos por um período no qual as nossas esperanças por uma ajuda terapêutica sejam limitadas, podemos, guiados pelo lento progresso da enfermidade, estendê-lo por uma longa duração, em comparação com o período ao qual seríamos obrigados a nos confinar na maioria das doenças.

No entanto, deve ser compreendido, como em muitos outros casos, que a resolução dos pacientes raramente será suficiente para possibilitar que eles perseverem pelo período de tempo que o processo proposto necessariamente exigirá. Tão lento quanto o progresso da doença, deve ser o período no qual haja a probabilidade de voltar à saúde. Na maioria dos casos, especialmente naqueles em que se permitiu a existência da doença sem oposição, pode-se descobrir que tudo o que tal parte é capaz de realizar é interromper o seu progresso futuro. Isso também não será considerada uma brincadeira, quando, por alusão à história da doença, verificar-se a lista de males inoportunos que poderiam ser assim evitados.

No entanto, parece haver razão para se esperar por mais. Para que a suposta mudança da estrutura ocorra, é extremamente provável que esta mudança possa ser apenas um aumento na massa ou no volume por meio da adição intersticial, a consequência do aumento da ação nos vasos sanguíneos da parte. Nesse caso, se a instituição de uma secreção purulenta em uma parte vizinha atuar de maneira que presumiríamos — se puder manter uma secreção constante — não apenas alterar a determinação, mas reduzir a ação desordenada dos vasos sanguíneos na parte doente, e ao mesmo tempo estimular os absorventes de tal aumento de ação, 
assim como remover a matéria acrescentada, haverá forte base para a esperança, que uma recuperação feliz, embora lenta, da saúde possa ser obtida.

Até que estejamos mais bem informados sobre a natureza desta doença, o emprego de medicamentos internos é pouco garantido, a menos que a analogia possa apontar alguma terapêutica, cujo teste a esperança racional possa autorizar. Circunstâncias particulares devem de fato surgir em casos diferentes, nos quais a ajuda de medicamentos possa ser necessária. A inteligência nunca falhará em beneficiar-se de qualquer oportunidade para fazer um teste sobre a influência do mercúrio, que manifestou em várias instâncias o seu poder em corrigir o desarranjo da estrutura.

Os poderes enfraquecidos dos músculos nas partes afetadas é um sintoma tão marcante, que pode levar a um erro do observador desatento, que pode considerar a doença mera consequência de uma constituição débil. Se essa noção for perseguida, e medicamentos tônicos e uma dieta altamente nutritiva forem recomendados, é provável que nenhum benefício seja assim obtido; já que a doença não depende da fraqueza geral, mas apenas da interrupção do fluxo da influência nervosa às partes afetadas.

Deve-se muito lamentar que esta enfermidade seja geralmente considerada pelos sofredores a partir desse ponto de vista, assim desencorajando o emprego de meios terapêuticos. Raramente ocorrendo antes da idade dos cinquenta e frequentemente produzindo poucos inconvenientes por vários meses, ela é geralmente considerada uma diminuição irremediável da influência nervosa, naturalmente resultante da vida em declínio e, portanto, terapias são raramente buscadas.

Embora incapaz de rastrear a conexão pela qual o estado desorganizado do estômago e dos intestinos pode induzir uma ação mórbida em uma parte da medula espinhal, ainda ensinado pela instrução do sr. Abernethy, deve haver pouca hesitação antes de determinarmos a probabilidade de tal ocorrência. $\mathrm{O}$ poder, possuído pela simpatia, de induzir tal ação desordenada em uma parte distante e a probabilidade de tal ação desordenada produzir o desarranjo da estrutura, dificilmente pode ser negado. O seguinte caso parece provar, pelo menos, que a influência simpática misteriosa que simula tão de perto as formas de outras doenças, pode induzir tais sintomas que poderiam ameaçar a formação de uma doença não diferente da que estamos aqui tratando.

$A$. $B$, um homem de 54 anos com hábitos moderados e estado regular dos intestinos, foi gradualmente afetado por uma leve dormência e sensação de alfinetadas, com um sentimento de fraqueza em ambos os braços, acompanhado de um senso de plenitude sobre os ombros, como se produzido pela pressão de uma forte ligadura e, às vezes, um leve tremor das mãos. Durante a noite, a plenitude, a dormência e as alfinetadas aumentavam muito. $\mathrm{O}$ apetite havia 


\section{CLÁSSICOS DA PSICOPATOLOGIA}

diminuído por várias semanas, e o abdômen, ao ser examinado, parecia conter acumulação considerável.

Antes da adoção de quaisquer outras medidas, e como parecia não haver marcas de plenitude vascular, determinou-se que os intestinos fossem esvaziados. Isso foi feito por meio de doses moderadas de calomel, com a ajuda ocasional de sais de Epsom, e em cerca de dez dias, apenas com esses meios, as queixas pararam por completo.

Antes de concluir estas páginas, é apropriado observar uma vez mais que um importante objeto que se propõe obter com as mesmas é chamar a atenção daqueles que humanamente empregam o exame anatômico na detecção das causas e da natureza das doenças, particularmente para esta enfermidade. Por meio de seu trabalho benevolente, sua natureza real pode ser determinada e modos apropriados de alívio, ou mesmo de cura, apontados.

Para tais pesquisas, já se deve muito à arte da cura por aumentar seus poderes de reduzir os males da humanidade que sofre. O público tem pouca consciência das obrigações que tem com aqueles que, movidos por ardor profissional e ditados pelo dever, devotaram as suas vidas a estas procuras, nas mais desagradáveis e proibitivas circunstâncias. Toda pessoa com consideração e sentimento pode julgar as vantagens produzidas pelos esforços filantrópicos de um Howard, mas poucos podem estimar os benefícios concedidos à humanidade pelos trabalhos de um Morgagni, Hunter ou Baillie.

Citação/Citation: Parkinson, J. (2016, março). Um ensaio sobre a paralisia agitante. Revista Latinoamericana de Psicopatologia Fundamental, 19(1), 123-149.

Editores do artigo/Editors: Prof. Dr. German E. Berrios

James Parkinson (1755-1824)

Cirurgião, político e paleontólogo amador inglês.

This is an open-access article, which permits unrestricted use, distri(cc) BY-NC bution, and reproduction in any medium for non-commercial purposes provided the original authors and sources are credited. 